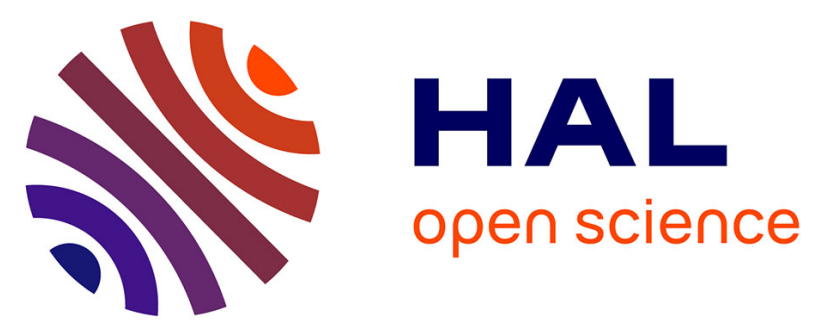

\title{
Assessment of global cloud datasets from satellites: Project and database initiated by the GEWEX radiation panel
}

C.J. Stubenrauch, W.B. Rossow, S. Kinne, S. Ackerman, G. Cesana, H. Chepfer, L. Di Girolamo, B. Getzewich, A. Guignard, A. Heidinger, et al.

\section{To cite this version:}

C.J. Stubenrauch, W.B. Rossow, S. Kinne, S. Ackerman, G. Cesana, et al.. Assessment of global cloud datasets from satellites: Project and database initiated by the GEWEX radiation panel. Bulletin of the American Meteorological Society, 2013, 94 (7), pp.1031-1049. 10.1175/BAMS-D-12-00117.1. hal-01091218

\section{HAL Id: hal-01091218 \\ https://hal.science/hal-01091218}

Submitted on 5 Dec 2014

HAL is a multi-disciplinary open access archive for the deposit and dissemination of scientific research documents, whether they are published or not. The documents may come from teaching and research institutions in France or abroad, or from public or private research centers.
L'archive ouverte pluridisciplinaire HAL, est destinée au dépôt et à la diffusion de documents scientifiques de niveau recherche, publiés ou non, émanant des établissements d'enseignement et de recherche français ou étrangers, des laboratoires publics ou privés. 


\section{ASSESSMENT OF GLOBAL CLOUD DATASETS FROM SATELLITES Project and Database Initiated by the GEWEX Radiation Panel}

by C. J. Stubenrauch, W. B. Rossow, S. Kinne, S. Ackerman, G. Cesana, H. Chepfer, L. Di Girolamo, B. Getzewich, A. Guignard, A. Heidinger, B. C. Maddux, W. P. Menzel, P. Minnis, C. Pearl, S. Platnick, C. Poulsen, J. Riedi, S. Sun-Mack, A. Walther, D. Winker, S. Zeng, and G. Zhao

Cloud properties derived from space observations are immensely valuable for climate studies and model evaluation, even though the statistics of some properties may be affected by inherent instrument capabilities or retrieval methodology.

$\mathrm{T}$ he Global Energy and Water Cycle Experiment (GEWEX) Radiation Panel (GEWEX Data and Assessment Panel since 2011) initiated the GEWEX Cloud Assessment in 2005 to compare available, global, long-term cloud data products with the International Satellite Cloud Climatology Project (ISCCP; Rossow and Schiffer 1999). ISCCP has been providing GEWEX cloud products since the 1980s. These were designed to characterize essential cloud properties and their variation on all key time scales to elucidate cloud dynamical processes and cloud radiative effects. The focus of the assessment is on the comparison of global climatological averages as well as their regional, seasonal, and interannual variations derived from level-3 (L3) cloud products (gridded monthly statistics). This decision was driven partly by the desire to provide an overview of cloud properties retrieved from space observations and partly by lack of funding. The outcome of the assessment also builds on level-2 comparisons independently undertaken by the different cloud teams [appendix 1 of Stubenrauch et al. (2012), and references therein]. The presentations and discussions during four international workshops led to the current GEWEX Cloud Assessment database, including
Affiliations: Stubenrauch, Cesana, Chepfer, and GuignardLaboratoire de Météorologie Dynamique/IPSL/CNRS, UPMC, Ecole Polytechnique, Palaiseau, France; Rossow and PEARL-CREST Institute, City College of New York, New York, New York; KINNE-Max Planck Institute for Meteorology, Hamburg, Germany; Ackerman, Maddux, Menzel, and Walther-CiMSS, University of Wisconsin-Madison, Madison, Wisconsin; DI GIROLAMO AND ZHAO-Department of Atmospheric Sciences, University of Illinois at Urbana-Champaign, Urbana, Illinois; GETZEWICH AND SUN-MACK-Science Systems and Applications, Inc., Hampton, Virginia; HEIDINGER-NOAA/NESDIS/STAR, Madison, Wisconsin; MINNIS AND WINKER-NASA Langley Research Center, Hampton, Virginia; PLATNICK-NASA Goddard Space Flight Center, Greenbelt,
Maryland; POULSEN-Rutherford Appleton Laboratory, Chilton, United Kingdom; RIEDI AND ZENG - Laboratoire d'Optique Atmosphérique/CNRS, Lille, France; CORRESPONDING AUTHOR: Dr. Claudia Stubenrauch, Laboratoire de Météorologie Dynamique, Ecole Polytechnique, F-91128 Palaiseau CEDEX, France

E-mail: stubenrauch@Imd.polytechnique.fr

The abstract for this article can be found in this issue, following the table of contents.

DOI:10.1175/BAMS-D-12-00117.I

In final form 9 November 2012

(C)2013 American Meteorological Society 
TABLE I. Participating datasets, type of sensors, local observation times, and time period in the GEWEX Cloud Assessment database.

\begin{tabular}{|c|c|c|c|c|}
\hline ISCCP & Multispectral imagers & 0300, 0900, I500, $2100 \mathrm{LT}$ & $1983-2007$ & Rossow and Schiffer 1999; version D \\
\hline AVHRR Pathfinder PATMOS-x & Multispectral imagers & $0130,0730,1330,1930 \mathrm{LT}$ & $1982-2009$ & $\begin{array}{l}\text { Heidinger et al. 2012; } \\
\text { Walther and Heidinger 2012; version } 5\end{array}$ \\
\hline MODIS Science Team & Multispectral imager & $0130,1030,1330,2230$ LT & $2001-09$ & $\begin{array}{l}\text { Menzel et al. 2008; } \\
\text { Platnick et al. 2003; collection } 5\end{array}$ \\
\hline MODIS CERES Science Team & Multispectral imagers & $0130,1030,1330,2230 \mathrm{LT}$ & $2003-08$ & Minnis et al. 20II; edition 2 \\
\hline HIRS-NOAA & IR sounders & $0130,0730,1330,1930 \mathrm{LT}$ & $1987-2006$ & Wylie et al. 2005; version I \\
\hline TOVS Path-B & IR sounders & $0130,0730,1330,1930 \mathrm{LT}$ & 1987-94 & $\begin{array}{l}\text { Stubenrauch et al. 2006; } \\
\text { Rädel et al. 2003; version } 2\end{array}$ \\
\hline AIRS-LMD & IR sounder & $0130,1330 \mathrm{LT}$ & $2003-09$ & $\begin{array}{l}\text { Stubenrauch et al. 20I0; } \\
\text { Guignard et al. 2012; version I }\end{array}$ \\
\hline CALIPSO Science Team & Lidar & $0130,1330 \mathrm{LT}$ & 2007-08 & Winker et al. 2009; version 2 \\
\hline CALIPSO-GOCCP & Lidar & $0130,1330 \mathrm{LT}$ & 2007-08 & Chepfer et al. 2010; version 2.1 \\
\hline POLDER & Multi-angle imager & I330 LT & $2006-08$ & $\begin{array}{l}\text { Parol et al. 2004; Ferlay et al. 2010; } \\
\text { collection 2- VI7.18 }\end{array}$ \\
\hline MISR & Multi-angle imager & $1030 \mathrm{LT}$ & $2001-09$ & Di Girolamo et al. 2010; version I \\
\hline ATSR-GRAPE & Multi-angle imagers & 1030 LT & $2003-09$ & Sayer et al. 20II; version 1.0 \\
\hline
\end{tabular}

TABLE 2. Cloud properties in the GEWEX Cloud Assessment database and their range. Statistics of these variables (monthly averages, day-today variability, and histograms) are provided for all clouds and separately stratified by cloud-top height category and by cloud thermodynamical phase (liquid and ice). Height stratification is defined by cloud-top pressures as in ISCCP (high level with CP $<440 \mathrm{hPa}$, midlevel with $440<\mathrm{CP}<680 \mathrm{hPa}$, and low level with CP > $680 \mathrm{hPa}$ ). Thermodynamical phase is distinguished by CT (ISCCP, TOVS Path-B, and AIRS-LMD), by spectral radiance differences (PATMOS-x, MODIS, and ATSR-GRAPE), or by polarization signature (POLDER and CALIPSO).

\begin{tabular}{|l|l|l|}
\hline Cloud amount (fractional cloud cover) & CA & $(0-\mathrm{I})$ \\
\hline Cloud temperature at top & CT & $(150-340 \mathrm{~K})$ \\
\hline Cloud pressure at top & CP & $(1,013-100 \mathrm{hPa})$ \\
\hline Cloud height (above sea level) & CZ & $(0-20 \mathrm{~km})$ \\
\hline Cloud IR emissivity & CEM & $(0-\mathrm{I})$ \\
\hline Effective cloud amount (CA weighted by CEM) & CAE & $(0-1)$ \\
\hline Cloud (visible) optical depth & COD & $(0-400)$ \\
\hline Cloud water path (liquid, ice) & CLWP, CIWP & $\left(0-3,000 \mathrm{~g} \mathrm{~m}^{-2}\right)$ \\
\hline Cloud effective particle size (liquid, ice) & CREW, CREI & $(0-200 \mu \mathrm{m})$ \\
\hline
\end{tabular}

This article presents a summary of average satellite cloud properties and their variability. The GEWEX Cloud Assessment database includes cloud properties retrieved from different satellite sensor measurements, taken at various local times and over various time periods (Tables 1 and 2). Table 3 summarizes the main characteristics of the cloud property retrievals (including spectral domain, spatial resolution, and retrieval method, as well as ancillary data used) leading to the 12 datasets that participated in the GEWEX Cloud Assessment monthly averages, a measure of synoptic variability as well as histograms at a spatial resolution of $1^{\circ}$ latitude $\times 1^{\circ}$ longitude. It was created in a network Common Data Form (netCDF) format by the participating teams and is available at the GEWEX Cloud Assessment website (http://climserv.ipsl.polytechnique.fr/gewexca/) together with a detailed report (Stubenrauch et al. 2012) describing the findings of the assessment analysis as well as the participating datasets.
(Table 1). The main findings about the different cloud properties are indicated as bullets throughout the article. Selected figures of retrieved cloud properties illustrate results for global averages; probability distributions; and their regional, seasonal, and interannual variations.

\section{SATELLITE REMOTE SENSING OF CLOUD \\ PROPERTIES. Only satellite observations are}




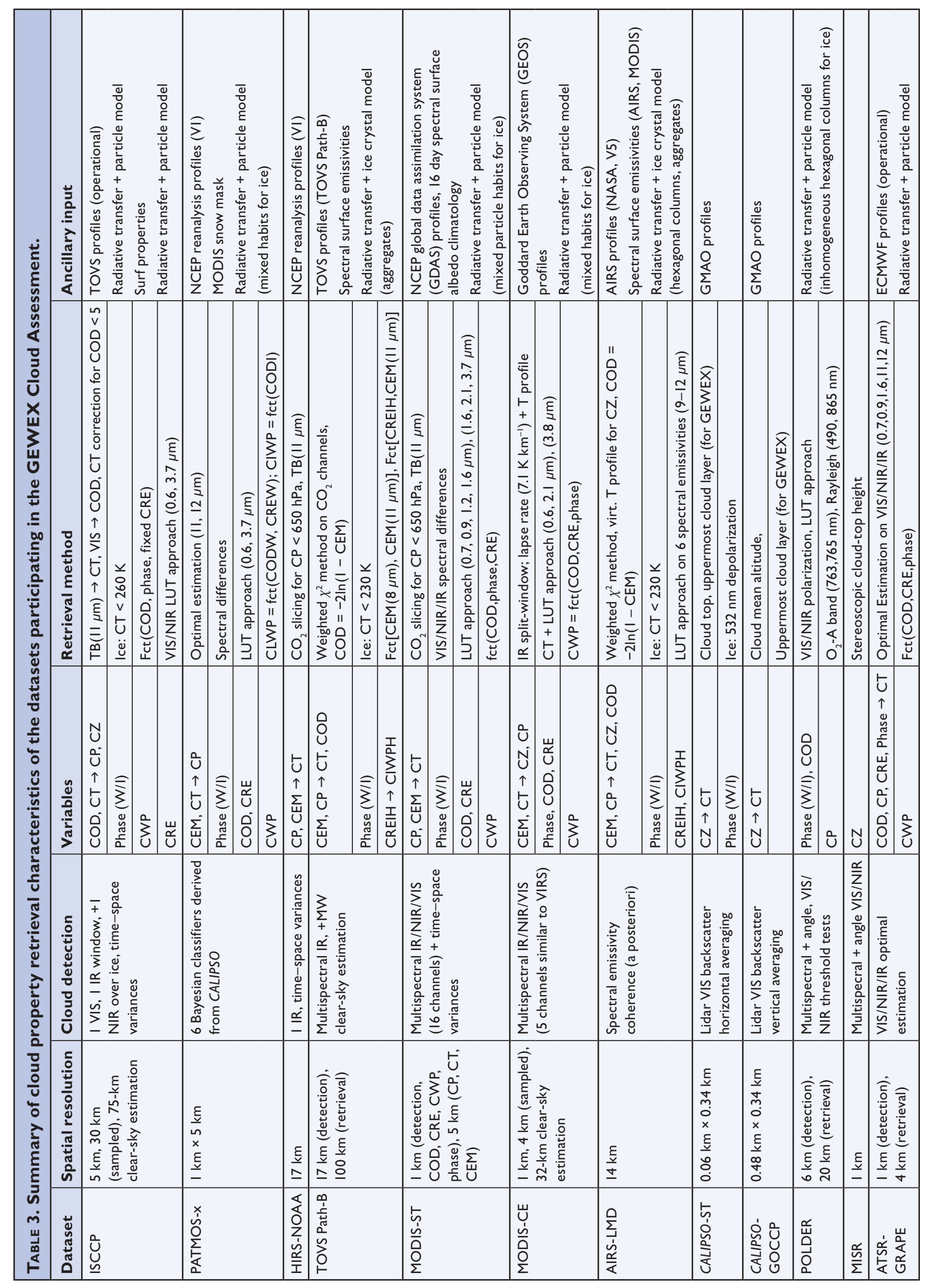


capable of providing a continuous synoptic survey of the state of the atmosphere over the entire globe. Operational weather satellite sensors have supplied data records extending more than 30 years. Whereas polar-orbiting cross-track scanning sensors generally only provide daily global coverage at particular local times of day, geostationary satellites are placed at particular longitudes along the equator and permit higher-frequency temporal sampling (15-min to 3 -h intervals).

The relevant passive satellite sensors measure radiation scattered or emitted by Earth's surface and by Earth's atmosphere including clouds. To maximize the sensitivity to the presence of clouds and to determine key cloud properties, specific spectral domains are exploited for particular retrieval methods. The conversion of the measured radiances into cloud properties generally requires two steps:

- cloud detection (or scene identification) and

- cloud property retrieval, often based on forward radiative transfer model computations and employing ancillary data to isolate the cloud radiative contributions from surface and noncloud atmospheric contributions

Clouds generally appear brighter and colder than Earth's surface. Cloudy scenes also generally exhibit larger spatial and temporal radiative variability than cloud-free or so-called clear-sky scenes; however, difficulties in detecting clouds may arise when the radiance contrast is small between the cloud and underlying surface (e.g., clouds over highly solar reflecting surfaces such as snow or ice, clouds with small thermal contrast to the surface below as for low-level clouds in humid boundary layers over ocean, or cloud edges) or when clear-sky scene variability is larger than usual (e.g., optically thin clouds over heterogeneous land areas or clouds over winter land areas).

Sensor types for retrieving cloud properties. Multispectral imagers are radiometers measuring in only a limited number of discrete bands, usually from the solar to thermal infrared wavelengths. Nadir viewing with cross-track scanning capabilities, they have a spatial resolution from about $0.25-7 \mathrm{~km}$ (at nadir) and are the only sensors that exist aboard both geostationary weather satellites and polarorbiting satellites. ISCCP uses a combination of these sensors from all available operational satellites to resolve the diurnal cycle of clouds. The only commonly available spectral bands are visible (VIS; day only) and infrared (IR) atmospheric window radiance measurements. Multispectral imagers aboard polar-orbiting satellites are the Advanced Very High Resolution Radiometer (AVHRR; with 5 spectral channels) aboard the National Oceanic and Atmospheric Administration (NOAA) satellites and the Meteorological Operation (MetOp) platforms of the European Organisation for the Exploitation of Meteorological Satellites (EUMETSAT) as well as the Moderate Resolution Imaging Spectroradiometer (MODIS; with 36 spectral channels) aboard the National Aeronautics and Space Administration (NASA) Earth Observing System (EOS) satellites Terra and Aqua. Measurements of the same scene under different viewing angles allow a stereoscopic retrieval of cloud-top height, which is employed routinely by the Multiangle Imaging SpectroRadiometer (MISR; with 4 solar spectral channels and 9 views) aboard Terra. Cloud thermodynamic phase can be determined (because nonspherical ice particles polarize the scattered light differently than liquid spherical droplets) using Polarization and Directionality of Earth's Reflectances (POLDER; with 8 solar subspectral channels-including 3 polarized-and up to 16 views), a sensor aboard A-Train's Polarization and Anisotropy of Reflectances for Atmospheric Sciences Coupled with Observations from a Lidar (PARASOL). Results from the Along-Track Scanning Radiometer (ATSR) and the Advanced Along-Track Scanning Radiometer (AATSR) (with 7 channels exploring solar to thermal infrared spectrum and 2 views) aboard the European Space Agency (ESA) platforms European Remote Sensing Satellite-2 (ERS-2) and Envisat, respectively, are also provided for the assessment, but only for daylight. A stereoscopic retrieval using ATSR/AATSR has not yet been developed.

IR sounders, originally designed for the retrieval of atmospheric temperature and humidity profiles, use IR channels in absorption bands of $\mathrm{CO}_{2}$, water vapor, and ozone. Measured radiances near the center of the $\mathrm{CO}_{2}$ absorption band are only sensitive to the upper atmosphere while radiances from the wing of the band are emitted from successively lower levels in the atmosphere. The operational High Resolution Infrared Radiation Sounder (HIRS; with 19 channels in the IR) aboard the NOAA satellites and the MetOp platforms of EUMETSAT is a multichannel radiometer, whereas the Atmospheric Infrared Sounder (AIRS) aboard Aqua and the Infrared Atmospheric Sounding Interferometer (IASI) aboard MetOp are newer infrared spectrometers. Their spatial resolution is about $15 \mathrm{~km}$ (at nadir). Several MODIS channels are similar to those of HIRS, allowing for a similar 
analysis but with higher spatial resolution. The variable atmospheric opacity of the many channels measured by these IR sounding instruments allows a more reliable identification of cirrus (semitransparent ice clouds), day and night. Sounder systems usually include microwave sounders [Microwave Sounding Unit (MSU) and Advanced Microwave Sounding Unit (AMSU)] as well. Because the latter operate at wavelengths insensitive to clouds (but sensitive to precipitation), they are also used in the retrieval of atmospheric profiles and may be used to improve cloud detection (by predicting IR clear-sky radiances; e.g., Scott et al. 1999).

Solar occultation limb sounders, such as the spectrometer of the Stratospheric Aerosol Gas Experiment II (SAGE II) aboard the NASA Earth Radiation Budget Satellite that measures occultation along Earth's limb at solar wavelengths, provide relatively good vertical resolution $(1 \mathrm{~km})$ at the expense of a low horizontal resolution along the viewing path (only about $200 \mathrm{~km}$ ). On the other hand, the long atmospheric pathlength permits the detection of subvisible (optically very thin) cirrus (Wang et al. 2001).

Passive microwave imagers, like the Special Sensor Microwave Imager (SSM/I) onboard satellites of the U.S. Air Force Defense Meteorological Satellite Program (DMSP) and the Advanced Microwave Sounding Radiometer for EOS (AMSR-E) aboard Aqua, have frequencies that are sensitive to cloud liquid water (and water vapor) as well as scattering by precipitation-sized ice particles. They may be used to estimate cloud liquid water path over ocean, if precipitation and drizzle contamination are removed (O'Dell et al. 2008).

Active sensors extend the measurements of passive radiometers to cloud vertical profiles. Since 2006 the Cloud-Aerosol Lidar and Infrared Pathfinder Satellite Observations (CALIPSO) lidar and CloudSat radar together determine cloud-top and cloud-base heights of all cloud layers (Stephens et al. 2002). Whereas the lidar is highly sensitive and can detect subvisible cirrus, its beam only reaches cloud base for clouds with an optical depth less than 3 . When the optical depth is larger, the radar is still capable of providing a cloud-base location; however, its signal is sensitive to clouds with an optical depth roughly greater than about 0.1 (Stephens et al. 2002). Even though the nadir-pointing active instruments have poor global sampling, the synergy with the passive instruments participating in the A-Train satellite formation (MODIS, AIRS, and POLDER) can be used to better study the vertical structure of different cloud types.
Description of datasets. To resolve the diurnal cycle of clouds the GEWEX cloud climate record, ISCCP emphasizes temporal resolution (eight observations per day) over spectral resolution. To achieve this goal with uniform global coverage, the only possibility is to use all of the imagers on the suite of geostationary and polar-orbiting weather satellites, which only have two wavelength channels in common in the VIS (day only) and the IR atmospheric window. For a better comparison with the other datasets in the assessment, the 8-times-daily ISCCP results have been averaged to four specific local observation times: 0300, 0900, 1500 , and 2100 LT. Cloud-top temperature (CT) is retrieved from the IR radiances. Cloud optical depth (COD) is obtained from the VIS radiances assuming effective particle radii (CRE) for liquid and ice clouds. In the standard ISCCP products, the daytime differences between the VIS-IR and IR-only cloud amounts are interpolated over the nighttime as a correction to the nighttime IR-only results; however, the products provided to the cloud assessment do not include this correction to better illustrate the differences between the two kinds of results. In addition, an experimental retrieval of CRE based on AVHRR measurements at $3.7 \mu \mathrm{m}$, based on the method developed by Han et al. (1994, 1999), is reported in the cloud assessment collection for comparison to other products. This product is not part of the standard ISCCP products but will be released separately. The cloud water path values reported in the cloud assessment are from the standard ISCCP products, COD and assumed CRE.

The Pathfinder Atmospheres Extended (PATMOS-x) was developed by NOAA to take full advantage of all five channels of the AVHRR sensor aboard the polarorbiting platforms of NOAA and of EUMETSAT. Cloud detection is based on Bayesian classifiers derived from CALIPSO (Heidinger et al. 2012), and the retrieval is based on an optimal estimation approach (Heidinger and Pavolonis 2009). First, cloud pressure (CP) and cloud emissivity (CEM) are retrieved using two IR channels at all times of day. Then COD and CRE are obtained from solar channels during daytime so that finally cloud water path (CWP) can be derived from COD and CRE (Walther and Heidinger 2012).

The Global Retrieval of ATSR Cloud Parameters and Evaluation (ATSR-GRAPE) cloud products (CP, COD, and CRE) are retrieved only during day, also using an optimal estimation approach on the five available VIS/NIR/IR channels (Sayer et al. 2011). CWP is derived from COD and CRE.

IR sounder data have been analyzed to obtain $\mathrm{CP}$ and CEM by using two approaches. HIRS-NOAA (Wylie et al. 1994, 2005) applies the " $\mathrm{CO}_{2}$ slicing" 
method at atmospheric pressures up to $650 \mathrm{hPa}$, complemented in the lower troposphere by the use of one IR atmospheric window radiance, while Television Infrared Observation Satellite (TIROS) Operational Vertical Sounder (TOVS) Path-B and AIRS-Laboratoire de Météorologie Dynamique (AIRS-LMD) (Stubenrauch et al. 1999b, 2006, 2010) apply a weighted $\chi^{2}$ method using the same $\mathrm{CO}_{2}$ absorbing channels within the whole troposphere. For the latter datasets, the retrieval of effective ice crystal radius (CREI) and cloud ice water path (CIWP) for cirrus is based on spectral emissivity differences between 8 and $12 \mu \mathrm{m}$ and a lookup table (LUT) approach (Rädel et al. 2003; Guignard et al. 2012).

MODIS cloud properties are retrieved by two teams. The MODIS Science Team (MODIS-ST) uses spectral testing to determine cloud amount (Ackerman et al. 1998; Frey et al. 2008), the $\mathrm{CO}_{2}$ slicing to determine CP and CEM (Menzel et al. 2008), and a LUT approach using solar reflectance channels to retrieve COD and CRE (Platnick et al. 2003). The MODIS Clouds and the Earth's Radiant Energy System (CERES) Science Team (MODIS-CE) uses IR radiances to determine CT and CEM and during the day a reflectance-based LUT approach to retrieve COD and CRE (Minnis et al. 2008a, 2011).

POLDER determines cloud thermodynamical phase (Goloub et al. 2000) and COD using VIS/ shortwave IR (SWIR) polarization and a LUT approach. CP is determined through differential absorption using two channels in the $\mathrm{O}_{2} \mathrm{~A}$ band (Ferlay et al. 2010).

MISR provides a stereoscopic cloud-top height (CZ) from multispectral and multi-angular VIS/ SWIR measurements (Di Girolamo et al. 2010), which does not rely on ancillary products.

The active lidar measurements of the CALIPSO mission are also analyzed by two teams. The CALIPSO Science Team (CALIPSO-ST) determines cloud-top height from VIS backscatter and identifies cloud ice from depolarization (Winker et al. 2009). Noise is reduced by horizontal averaging. The GCMOriented CALIPSO Cloud Products (CALIPSOGOCCP) reduce noise by vertical averaging (Chepfer et al. 2010).

Table 3 summarizes the main characteristics of these cloud property retrievals and detailed retrieval descriptions may be found in the references of Table 1 and in the GEWEX Cloud Assessment report (annex 1 in Stubenrauch et al. 2012).

CLOUD AMOUNT. Cloud amount (CA), which is often referred to as cloud cover or cloud fraction, is the ratio between the number of samples that contain clouds and the total number of measured samples. How instrument resolution (footprint size) affects the estimate of cloud amount has been studied by Wielicki and Parker (1992), Di Girolamo and Davies (1997), Rossow et al. (1993), and Maddux et al. (2010): one would expect an increase in CA by decreasing the spatial resolution (with the same detection sensitivity), especially in the case of low-level clouds, which can be broken and more variable at smaller scales than upper-level clouds. However, the total cloud amount determined by a particular instrument also depends on the sensitivity of its measurements to the presence of clouds.

The global total cloud amount, presented in Fig. 1, varies between 0.56 (POLDER) and 0.74 (HIRSNOAA). This range is mainly explained by different instrument sensitivity and by retrieval methodology. The main findings concerning total cloud amount are as follows:

- Global total cloud amount (Fig. 1) is about 0.68 $( \pm 0.03)$ when considering clouds with optical depth $>0.1$ (retrieval sensitivity of ISCCP during day, PATMOS-x, MODIS-ST, AIRS-LMD, HIRSNOAA, TOVS Path-B, and CALIPSO-GOCCP; cloud detection of MODIS-CE and MISR is slightly less sensitive over land). This value increases to about 0.73 when including subvisible cirrus (CALIPSO-ST) and decreases to about 0.56 for clouds with optical depth $>2$ (POLDER). The optimal estimation method of ATSR-GRAPE leads to a slight underestimation (0.62), because only clouds with small uncertainty are reported (based on a single cloud layer model).

- The typical global interannual variability in CA is about 0.03 , about 10 times smaller than the typical local day-to-day variability over the globe.

- According to most datasets, oceans are covered by about $0.10-0.15$ more cloud than land. Only HIRS-NOAA and MISR detect a larger oceanland difference of 0.30 , which can be attributed to lowered sensitivity for cloud detection over land (HIRS misses low-level clouds and MISR misses optically thin cirrus) and to diurnal sampling bias for MISR, which samples only morning conditions (+0.07: due to slightly larger CA over ocean and significantly smaller CA over land in the morning compared to the afternoon).

- The latitudinal variation in CA (Fig. 2) of all datasets agrees well [except for polar regions and HIRS-NOAA in Northern Hemisphere (NH) midlatitudes], indicating subtropical subsidence regions 
FIG. I. (top) Global averages of total CA, as well as fraction of high-level, midlevel, and low-level cloud amount relative to total cloud amount (CAHR + CAMR + CALR = I). The sketch illustrates the cloud height interpretation in the case of optically thin cirrus overlying low-level clouds (less than $20 \%$ of all cloudy scenes according to CALIPSO) when using different instruments. (bottom) Global averages of effective cloud amount (cloud amount weighted by cloud emissivity) of high-level clouds, of midlevel clouds, and of low-level clouds. Statistics are averaged over daytime measurements (I330-I500 LT, except MISR and ATSR-GRAPE at 1030 LT).
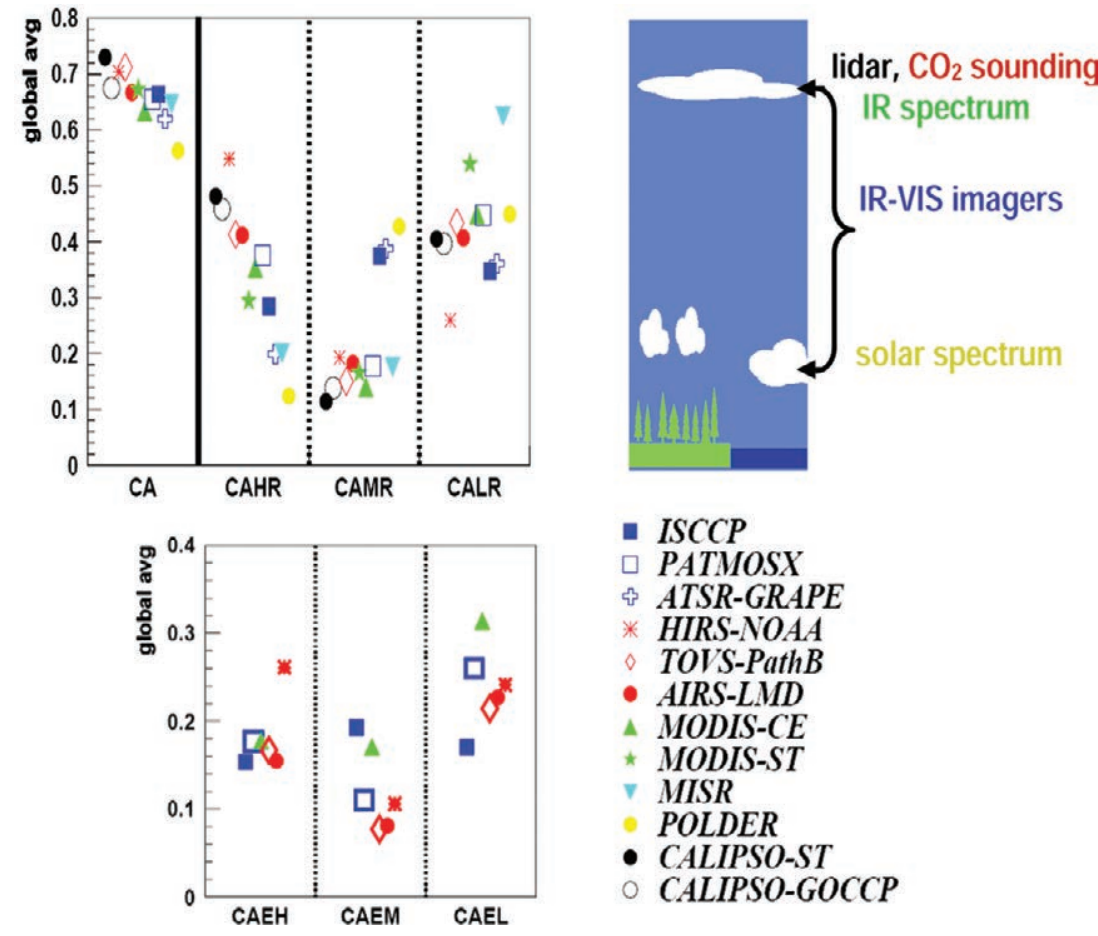

- ISCCP

- PATMOSX

\& ATSR-GRAPE

* HIRS-NOAA

$\checkmark$ TOVS-PathB

- AIRS-LMD

$\triangle$ MODIS-CE

* MODIS-ST

$\checkmark$ MISR

POLDER

- CALIPSO-ST

- CALIPSO-GOCCP
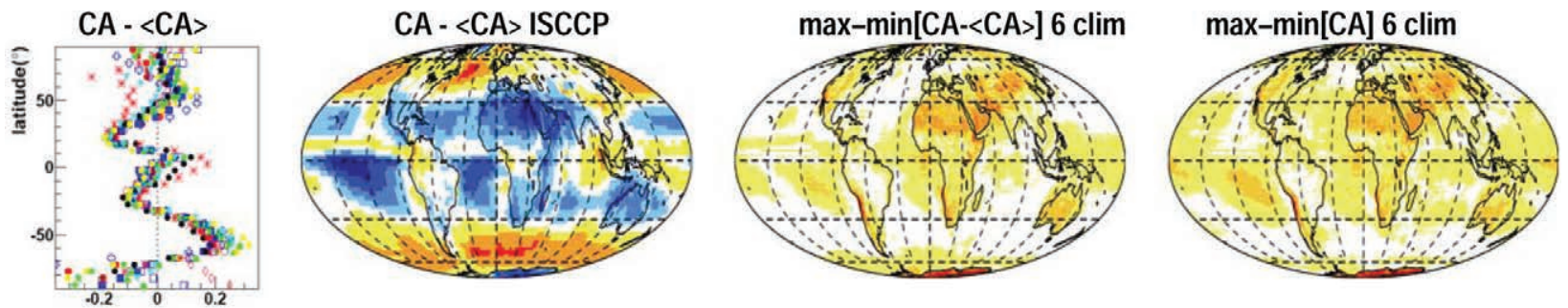

CAHR - $<$ CAHR $>$
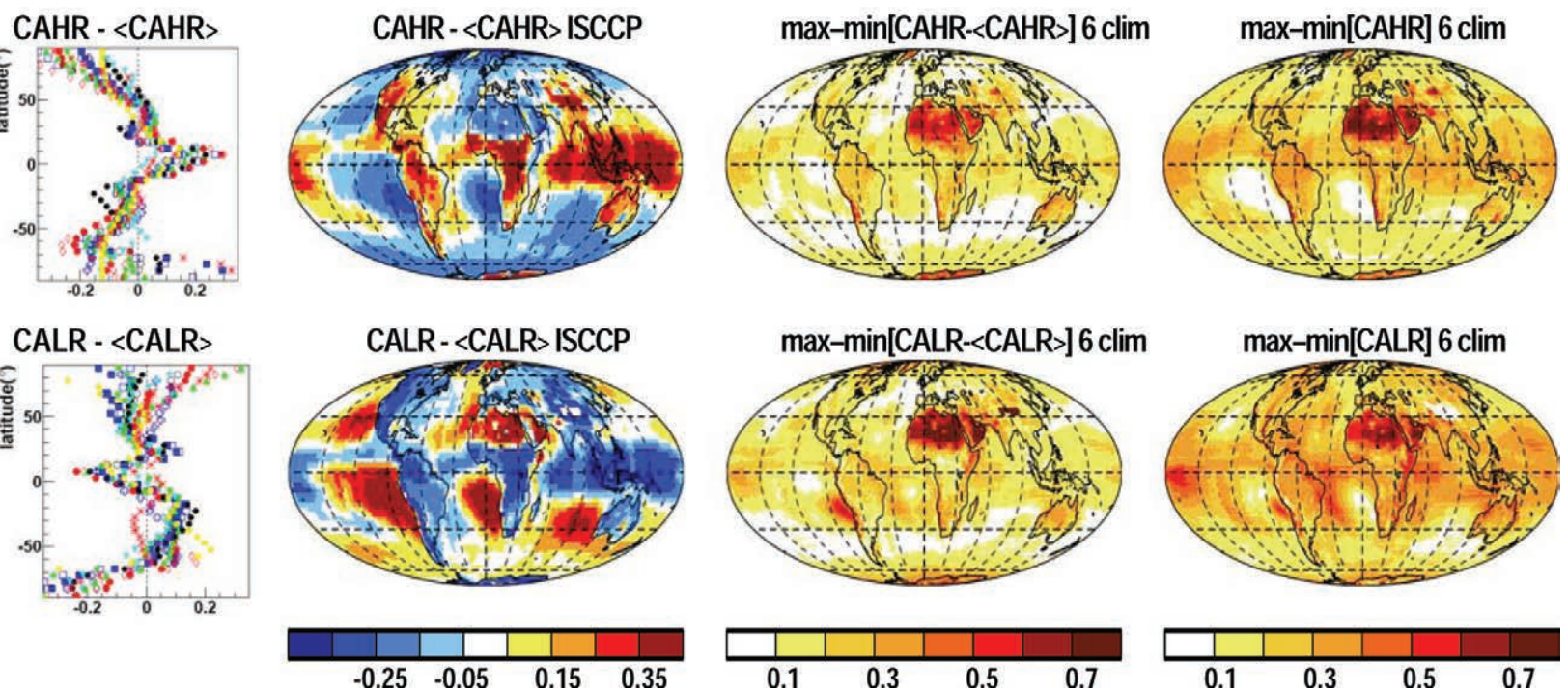

FIG. 2. (left) Latitudinal variations relative to global annual mean of all cloud datasets (legend as in Fig. I), (middle left) ISCCP regional variations relative to global annual mean; and regional spreads between maximum and minimum within six cloud datasets (ISCCP, PATMOS-x, MODIS-ST, MODIS-CE, AIRS-LMD, and TOVS Path-B), in (middle right) a relative and (right) an absolute sense, of (top) CA, (middle) CAHR, and (bottom) CALR. Statistics are averaged over all measurements in (left) and only over daytime measurements at I330-I500 LT for (middle left)-(right). Numbers correspond to fractions. 
with about 0.10 and 0.15 less cloudiness than the global mean at around $20^{\circ} \mathrm{N}$ and $20^{\circ} \mathrm{S}$, respectively, and the storm regions in the Southern Hemisphere (SH) midlatitudes with $0.15-0.25$ more cloudiness than the global mean at around $60^{\circ} \mathrm{S}$.

The regional variations of CA with respect to the global annual mean, as determined by ISCCP, confirm these patterns (Fig. 2).

Derived cloud amounts depend on instrument capabilities and retrieval performance. To illustrate the range due to differing sensor sensitivities and retrieval methodologies, Fig. 2 presents local differences between maximum and minimum CA (both relative to global annual mean $\mathrm{CA}$ and absolute) of six datasets (ISCCP, PATMOS-x, MODIS-ST, MODIS-CE, AIRS-LMD, and TOVS Path-B). The six datasets have been chosen after eliminating datasets taking data at different observation times (MISR and ATSR-GRAPE) and two outliers (HIRS-NOAA, with low sensitivity to low-level clouds, and POLDER, only providing information for clouds with optical depth $>2$; Zeng et al. 2011). The CALIPSO datasets were eliminated because of their large sampling noise at $1^{\circ}$ latitude $\times 1^{\circ}$ longitude (Astin et al. 2001). The global range in CA of these six datasets corresponds to only 0.08 (Fig. 1); however, locally, differences in detecting clouds within the datasets may reach 0.4 over deserts and mountains. Another feature is the intertropical convergence zone (ITCZ), where different sensitivities to thin cirrus lead to a range of about 0.15 in CA. The subtraction of the global annual means from the considered datasets leads to slightly improved difference patterns in CA, emphasizing the good agreement for latitudinal variation.

CLOUD-TOP LOCATION. Cloud-top location can be retrieved in terms of CT, CP, or CZ above mean sea level. The conversion among these variables requires atmospheric temperature profiles, which are either retrieved (e.g., for TOVS Path-B and AIRSLMD) or adopted from reanalyses [e.g., from National Centers for Environmental Prediction (NCEP) for PATMOS-x, MODIS-ST, and HIRS-NOAA or from European Centre for Medium-Range Weather Forecasts (ECMWF) for ATSR-GRAPE] or taken from weather forecasts [e.g., from Global Modeling and Assimilation Office (GMAO) for MODIS-CE and CALIPSO]. ISCCP uses an observation-based operational product from TOVS. Differences in monthly statistics can arise from differences in these ancillary datasets (e.g., Minnis et al. 1992, 1993; Jin and Rossow 1997; Stubenrauch et al. 1999a; Wang et al. 1999) but also because of differing detection sensitivity to thin, high clouds.

In general, passive remote sensing provides cloud properties as observed from above. Therefore, high-level clouds correspond to all high-level cloud situations, including single and multiple cloud layers, whereas midlevel and low-level clouds correspond only to situations with no higher altitude clouds above. Cloud-top height can be accurately determined with lidar (e.g., CALIPSO).

Apart from the MISR stereoscopic height retrieval for optically thicker clouds, passive remote sensing provides a "radiometric height," lying near the middle between cloud top and "apparent" cloud base. The latter corresponds to the real cloud base when optical depth is smaller than 3. The "radiometric height" may lie as much as a few kilometers below the "physical height" of the cloud top, depending on the cloud extinction profile and vertical extent (e.g., Liao et al. 1995; Wang et al. 1999; Sherwood et al. 2004; Holz et al. 2006; Minnis et al. 2008b; Stubenrauch et al. 2010). High-level clouds in the tropics generally have such "diffusive" cloud tops (meaning that the optical depth increases only slowly from cloud top downwards) for which retrieved cloud temperature may be as much as $10 \mathrm{~K}$ larger than the cloud-top temperature corresponding to a lidar height (Fig. 3).

Most sensors with only atmospheric IR window channels retrieve cloud-top temperature, assuming that clouds act as blackbody emitters (especially lowlevel clouds). For semitransparent clouds the retrieved cloud temperature is therefore biased high because of atmospheric and surface radiation passing through these clouds and needs to be corrected. This can be done by using information on the cloud VIS optical depth or IR emissivity. In the case of multiple cloud layers, this correction will be underestimated (Jin and Rossow 1997).

Methods involving differential measurements in strong absorption bands $\left(\mathrm{CO}_{2}\right.$ or $\left.\mathrm{O}_{2}\right)$ determine cloud-top pressure. Whereas the sounding of the thermal $\mathrm{CO}_{2}$ absorption band leads to a $\mathrm{CP}$ corresponding to the radiometric top, the use of the solar $\mathrm{O}_{2}$ absorption band corresponds to the middle of the cloud (Ferlay et al. 2010).

Probability density functions (PDFs) of CP and CT are obtained by normalizing the histograms available in the cloud assessment database by the number of cloudy samples. Thus, they reflect how the detected clouds are vertically distributed in the atmosphere. The PDFs of CT and CP in Fig. 3 show a bimodal structure, especially in the tropics. This is the reason why average values of $\mathrm{CP}$ and CT may be ambiguous 
and why it is better to use, in addition to averages over all clouds, height-stratified averages.

The decrease of bimodality and range in $\mathrm{CP}$ and $\mathrm{CT}$ from tropics towards poles, shown by all datasets but HIRS-NOAA, is essentially linked to the decrease of the tropopause height and a change in the type of atmospheric storm from convective to baroclinic cyclone. The strong bimodality in the tropics, which is well represented by MODIS-ST, AIRS-LMD, HIRS-NOAA, and PATMOS- $\mathrm{x}$ with strong peaks at $950 \mathrm{hPa}$ and between 250 and $150 \mathrm{hPa}$, also means that the tropics have few midlevel clouds, in agreement with local observations using groundbased radar (Mace and Benson-Troth 2002) and with CALIPSO-CloudSat observations (Mace et al. 2009). CP distributions of POLDER and ISCCP are flatter with a larger amount of midlevel clouds (see next section).

CALIPSO is the only mission providing accurate height for cloud top, even for optically very thin clouds such as subvisible cirrus. Therefore the radiative cloud height retrieved by passive remote sensing should lie below the CALIPSO cloud height. This applies especially to high-level clouds with diffusive tops, frequently found in the tropics. In addition, the amplitude of the maximum frequency of occurrence should be smaller because of missed subvisible cirrus. These criteria are fulfilled by most of the datasets. The peak of ISCCP at very low temperature is explained by the fact that the ISCCP retrieval sets the cloud height to just above the tropopause for optically thin cirrus. A very sharp peak of PATMOS-x in the tropics at $215 \mathrm{~K} / 150 \mathrm{hPa}$ seems suspect even though the PATMOS-x retrieval had been trained by CALIPSO data. Note that when CALIPSO and CloudSat observations are combined a more complete view of cloud vertical structure is obtained (Mace et al. 2009).

\section{HEIGHT-STRATIFIED CLOUD AMOUNT.}

Height-stratified cloud amount relative to total cloud amount gives another indication of how the detected clouds are vertically distributed in the atmosphere. It is less influenced by differences in cloud detection sensitivity and should also be more useful for comparison with climate models, which tend to underrepresent the optically thinner clouds (e.g. Hendricks et al. 2010; Su et al. 2011).

The global average fraction of high-level clouds out of all detected clouds varies from $12 \%$ to $55 \%$ (CAHR; Fig. 1). This range is essentially explained by instrument sensitivity to detect and/or identify thin cirrus, especially when overlying low-level clouds (about $20 \%$ of all cloudy situations according to CALIPSOST data): Active lidar measurements, IR sounding along the $\mathrm{CO}_{2}$ absorption band, and methods using IR spectral differences are powerful for thin cirrus identification (with descending sensitivity from the 
former to the latter). Solar reflectance information is more important for the detection of low-level clouds. Thus, the use of different spectral domains is identified as the main reason for discrepancies in retrieved cloud properties, and these can be understood as cloud scene dependent uncertainties and biases. For cases when thin cirrus is overlying low-level clouds, different retrievals provide different answers: Active lidar and IR methods determine the cloud properties of the thin cirrus (CALIPSO-ST, CALIPSO-GOCCP, HIRS-NOAA, TOVS Path-B, AIRS-LMD, MODISST, MODIS-CE, and PATMOS-x), IR-VIS methods (ISCCP and ATSR-GRAPE) provide the properties corresponding to a radiative mean from both clouds, and VIS-only methods emphasize the clouds underneath (MISR and POLDER).

- About 40\%-50\% of all clouds are high-level clouds, when considering instruments deemed most sensitive to thin cirrus. [Outliers are HIRS-NOAA (55\%: underestimation of low-level clouds leads to overestimation of fraction of high-level clouds) and POLDER (12\%: misidentification of high-level clouds as midlevel clouds, because $\mathrm{CP}$ determined by $\mathrm{O}_{2}$ absorption corresponds to a deeper level within the cloud).]

- Only about $15 \%( \pm 5 \%)$ of all clouds correspond to midlevel clouds with no higher clouds above (CAMR; Fig. 1). [Values of POLDER (43\%), ATSRGRAPE (39\%), and ISCCP (27\%) for midlevel cloud amounts are biased high, because of misidentification of high-level clouds overlying lower-level clouds.]

- According to the majority of datasets, about $40 \%( \pm 3 \%)$ of all clouds are single-layer low-level clouds (CALR; Fig. 1). [Outliers are HIRS-NOAA with $26 \%$ (IR window brightness temperature compared to surface air temperature from NCEP reanalysis may lead to underestimation of low-level clouds, especially over land) and MODIS-ST with $53 \%$ (due to misidentification of optically thin cirrus; Holz et al. 2006).]

By using solar reflectances alone from multiple view angles, MISR accurately determines the height of the low-level cloud even when thin cirrus is present above. This leads to a relative low-level cloud amount of about $60 \%$, in agreement with $57 \%$ from CALIPSOGOCCP when not only the uppermost clouds but all cloud layers within the atmosphere are considered. This means that about one-third of the coverage of all low-level clouds is overlapped by semitransparent higher-level clouds (also found from the frequency of occurrence of semitransparent cirrus overlying clouds at lower levels determined by CALIPSO-ST; cf. Jin and Rossow 1997). The merged CALIPSOCloudSat study by Mace et al. (2009) provides more definitive statistics of multilayer clouds.

- Whereas absolute values of height-stratified cloud amount depend on instrument sensitivity, geographical distributions and latitudinal variations (Fig. 2) of all datasets show very similar features. [Exceptions are polar regions (CAHR in $\mathrm{SH}$ and CALR in NH) and CALR of HIRS-NOAA. The range in regional differences between maximum and minimum CAHR and CALR (again relative to their global annual mean and absolute) of the six chosen participating cloud datasets (as for CA; see above) is due to different sensor sensitivity and retrieval methodology (third and fourth columns of Fig. 2). Whereas the global range in CAHR and CALR of these datasets correspond to about 0.2 (Fig. 1), the local range of CAHR and CALR may reach even 0.4 (ITCZ and deserts). However, considering variations instead of absolute values (by subtracting global annual means of the considered datasets) leads to a range mostly less than 0.2 (slightly smaller for CAHR than for CALR).]

\section{CLOUD RADIATIVE AND BULK MICRO- PHYSICAL PROPERTIES. CEM is retrieved at} thermal wavelengths, and values lie between 0 and 1 . Its global average is about 0.7 (varying from 0.6 to 0.8 ).

Effective cloud amount (CAE; cloud amount weighted by cloud emissivity) includes the IR radiative effect of the detected clouds. Its global average is about 0.50 . The global effective amount of high-level clouds (0.15) agrees much better between the different datasets than CAHR, because a smaller cloud amount due to missing thin clouds is compensated by a larger average cloud emissivity (Fig. 1). Nevertheless, for model evaluation it is better to compare both cloud amount and effective IR emissivity (or VIS optical depth) and not only averages but also distributions (see below).

Since cloud liquid droplets and ice crystals have different optical properties (linked to refractive index, particle shape, and size), it is necessary to distinguish the cloud thermodynamic phase before retrieving cloud optical depth and bulk microphysical properties. Liquid and ice clouds are distinguished by polarization measurements (POLDER and CALIPSO), by cloud temperature (ISCCP, AIRS-LMD, and TOVS Path-B), or by use of multispectral information (PATMOS-x, MODIS, and 

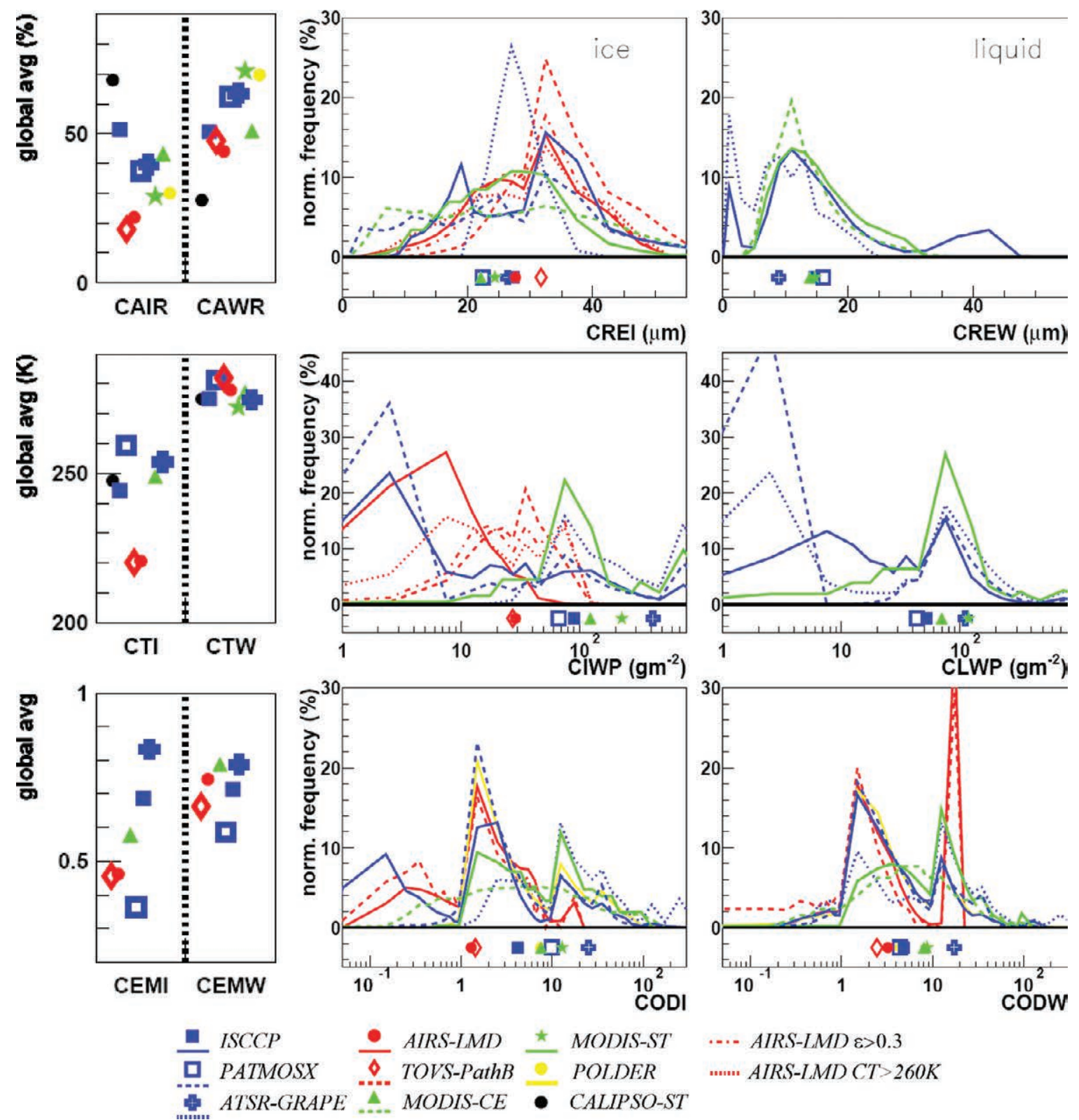

... AIRS-LMD $\varepsilon>0.3$

...... AIRS-LMD CT $>260 \mathrm{~K}$

Fig. 4. (left) Global averages of cloud properties of ice clouds (I) and of liquid clouds (W): CAR, CT, and CEM. CAWR + CAIR $=100 \%$, except AIRS-LMD and TOVS Path-B, for which the missing $35 \%$ correspond to clouds of mixed phase $(230<C T<260 \mathrm{~K})$. (right) Normalized frequency distributions of cloud properties of I and W: CRE, CWP, and COD. Their global averages are indicated below the distributions. Statistics are averaged over daytime measurements (1330-I500 LT, except ATSR-GRAPE at 1030 LT).

ATSR-GRAPE). As shown in Fig. 4, the global average fraction of ice clouds relative to all clouds (CAIR) lies between $20 \%$ (corresponding to pure ice clouds colder than $230 \mathrm{~K}$, excluding mixed-phase clouds, and thus likely an underestimate) and 70\% (lidar backscatter depolarization), with values around 35\% when spectral variation methods are used. Average cloud temperature of definite ice clouds (colder than $230 \mathrm{~K}$ ) is about $220 \mathrm{~K}$. When warmer ice clouds and possibly mixed-phase clouds are included in the ice cloud category (all datasets but TOVS Path-B and AIRS-LMD), the average ice cloud temperature is about $250 \mathrm{~K}$ (Fig. 4).

COD is usually retrieved from a non-absorbing solar reflectance channel $(0.5-0.9 \mu \mathrm{m})$ and therefore only available during daytime, but higher time resolution results from geostationary observations do suggest systematic diurnal variations (Rossow and 
Schiffer 1999). Given the strong nonlinear relationship between reflectance and COD, the most accurate COD values lie between 2 and 100 .

Whereas CWP is a function of COD and CEM (although the latter function saturates), CRE (averaged over a size distribution within the cloud) can be obtained from spectral dependency in absorption and scattering in the solar or thermal domain, especially when particles are smaller. At constant CWP, decreasing CRE results in a larger solar albedo. Optical methods determine CRE for all cloud types. However, in the case of optically thick clouds CRE only relates to the upper part of the cloud. This may introduce CRE biases (typically overestimates for liquid clouds and underestimates for ice clouds). Other sources of uncertainty are assumed particle shape and size distribution within the cloud. Height contributions of CRE depend on the absorbing spectral band used in the retrieval (Platnick 2000): in general, absorption increases with increasing wavelength into the short- and mid-wave infrared (Platnick et al. 2003). IR sounders provide estimates of CRE only for semitransparent cirrus. CWP can be estimated from COD if CRE is known. ISCCP assumes values of CRE (different for liquid and ice clouds) for its retrieval of COD and its calculation of CWP. Experimental ISCCP results for CRE are presented based on an analysis of AVHRR data. Methods retrieving CRE and COD simultaneously should provide a better estimate.

Global COD varies between 4 and 10 (Fig. 4). Given a global mean cloud amount of nearly 0.70 , the radiative mean COD has to be $<5$ to give a planetary albedo near 0.3 (see section 3.5.3 of Stubenrauch et al. 2012). Retrieval filtering by MODIS-ST to exclude partly clouds pixels in broken low cloud regions results in larger mean COD compared to other datasets (Zhang and Platnick 2011; Pincus et al. 2012); in addition, MODIS-ST COD is truncated to 100 , resulting in a low mean bias for the thickest convective cloud regions relative to other datasets using higher truncation limits. For ATSR-GRAPE, the optimal estimation retrieval method, only successful for about $40 \%$ of all clouds, with a bias towards optically thick clouds, leads to larger COD averages. For comparison, CEM determined by IR sounders was converted to COD, which is then limited to values $\leq 10$ and therefore leads to smaller COD averages.

- Since PDFs of COD are not Gaussian (Fig. 4) and averages depend on pixel-level filtering choices before/after the retrieval, it is strongly recommended for comparisons with climate models that the distributions be considered instead of averages. [One can distinguish three groups in the distributions of Fig. 4: clouds with $\mathrm{COD}<1$, with COD between 1 and 10, and with COD $>10$. The main contribution to global averages comes from clouds with COD between 1 and 10 (except ATSR-GRAPE), and the relative contributions outside this range essentially reflect differences in data selection for the retrieval.]

- Global effective particle radii are about $14( \pm 1)$ and $25( \pm 2) \mu \mathrm{m}$ for the tops of liquid clouds and for high-level ice clouds, respectively (Fig. 4).

- Effective cloud droplet radii (CREW) are on average about $15 \%-20 \%$ larger over ocean than over continents, whereas the difference in CREI is only about 5\%. [All PDFs of effective cloud droplet radius (CREW) show a large peak around $11 \mu \mathrm{m}$. Additional smaller peaks around 2 (ISCCP and PATMOS-x) and $40 \mu \mathrm{m}$ (ISCCP) can be explained by partly cloudy samples and by thermodynamic phase misidentification, respectively.]

Assumptions on ice crystal shape lead to additional uncertainties in retrieved effective ice crystal radius (cf. Rädel et al. 2003; Zhang et al. 2009; Zeng et al. 2012): ISCCP, TOVS Path-B, and ATSR-GRAPE assume ice crystal aggregates, whereas the MODIS-ST collection 5 processing uses a mixture of ice crystal shapes and MODIS-CE assumes distributions of hexagonal columns. Assessing ice scattering models by POLDER led to the conclusion that nonpristine habits appear to be the rule (Baran and Labonnote 2007; Cole et al. 2012). AIRS-LMD estimates the most probable shape between ice crystal aggregates and pristine hexagonal columns, with the fraction of aggregates generally increasing with CIWP (Guignard et al. 2012).

The PDFs of CREI (Fig. 4) fall into two categories: those using the spectral absorption at IR $(8.7 \mu \mathrm{m}$ : TOVS Path-B and AIRS-LMD) or MWIR (3.7 $\mu \mathrm{m}$ : ISCCP, PATMOS- $x$, and MODIS-CE) and those using SWIR $(2.1 \mu \mathrm{m}$ : MODIS-ST; $1.6 \mu \mathrm{m}$ : ATSRGRAPE) channels. PDFs of the first category exhibit a large peak around $32 \mu \mathrm{m}$ with a plateau down to $20 \mu \mathrm{m}$, whereas PDFs of the second category exhibit a peak around $27 \mu \mathrm{m}$. Spectral absorption increases slightly with wavelength, so that by using shorter wavelengths one would expect to retrieve a CREI slightly deeper inside the cloud, leading to larger CREI (ice crystal size increases from cloud top to base due to aggregation processes), when the cloud statistics are similar (Yang et al. 2005; Zhang et al. 2010; Yang et al. 2013). Therefore, smaller peak values 
of CREI retrieved by MODIS-ST and ATSR-GRAPE may again be explained by retrieval filtering, because CREI is retrieved closer to the cloud top in the case of optically thicker clouds. A smaller peak at CREI of around $18 \mu \mathrm{m}$ produced by ISCCP can be probably explained by misidentified liquid clouds (or mixedphase clouds).

- Global cloud water path varies from 30 to $60 \mathrm{~g} \mathrm{~m}^{-2}$ for liquid clouds and from 60 to $120 \mathrm{~g} \mathrm{~m}^{-2}$ for clouds with ice tops (Fig. 4). Note that these values for ice clouds include all of the cloud water in the column, some of which may actually be liquid (cf. Lin and Rossow 1996; Lin et al. 1998; Mace et al. 2009). Retrieval filtering of ice clouds leads to smaller $\left(25 \mathrm{~g} \mathrm{~m}^{-2}\right.$ for semitransparent cirrus from AIRS-LMD) or larger values ( $225 \mathrm{~g} \mathrm{~m}^{-2}$ for clouds with optical depth larger than 1 from MODIS-ST). PDFs of CLWP of all datasets have a peak around $70 \mathrm{~g} \mathrm{~m}^{-2}$. A second peak around smaller values $\left(1.5 \mathrm{~g} \mathrm{~m}^{-2}\right.$ for PATMOS-x and ATSR-GRAPE and $8 \mathrm{~g} \mathrm{~m}^{-2}$ for ISCCP) may partly stem from partly cloudy samples or cloud edges.

- PDFs of CIWP depend strongly on retrieval filtering, with largest peaks around $5 \mathrm{~g} \mathrm{~m}^{-2}$ from datasets with no subsampling (ISCCP and PATMOS-x). Peaks move to 10 and $30 \mathrm{~g} \mathrm{~m}^{-2}$ when excluding clouds with CEM $<0.2$ (corresponding to COD < 0.45; AIRS-LMD) and CEM $<0.3$ (corresponding to $\mathrm{COD}<0.7$; TOVS Path- $\mathrm{B}$ ), respectively. The peak value is at $70 \mathrm{~g} \mathrm{~m}^{-2}$ when excluding clouds with COD $<1$ (MODIS-ST).

- The latitudinal variation of the retrieved cloud bulk microphysical properties is essentially expressed by the relative height of the peaks at smaller and larger values (section 3.2.2 of Stubenrauch et al. 2012). This means that the variation (especially of CIWP) is directly linked to the difference in occurrence of optically thin and thick clouds included in each product.

TIME VARIATIONS. The GEWEX Cloud Assessment was mainly focused on monthly averages and longer-term variations. However, diurnal variations can affect these results. Day-night differences and daytime sampling differences among datasets with no change in method (IR sounders and lidar) reflect random differences of a few percent (section 3.1.3 in Stubenrauch et al. 2012). CALIPSO seems to have a slightly smaller detection sensitivity for optically thin cirrus during the day $(5 \%-10 \%$ in CAHR over tropical land), linked to solar radiance noise. Day-night differences for ISCCP correspond to $5 \%-10 \%$ in CA over land (corrected by temporal interpolation in the official ISCCP version) and approach $25 \%$ in CAHR in the tropics, with the latter due primarily to the inability to adjust the height for transmissive clouds without COD information (both of these effects corrected for in the official ISCCP product). Seasonal variations are in general smaller than latitudinal variations, except for the transition of the ITCZ toward the summer hemisphere, which produces relative CA and CAIR changes of about $10 \%$ and $40 \%$ amplitude in the latitude band $0^{\circ}-30^{\circ} \mathrm{S}$ (our Fig. 5 and section 3.1.2 in Stubenrauch et al. 2012). In the $\mathrm{NH}$ midlatitudes the seasonal CA change has an amplitude of about $15 \%$, with a minimum of cloudiness in late summer, whereas in the SH midlatitudes it is negligible. Whereas seasonal variation of ice water path shows a similar phase as the one of ice cloud occurrence (except PATMOS-x in the tropics), the seasonal cycle of effective crystal radius is generally small (except MODIS-CE in midlatitudes). The large amplitude in CAIR in the SH midlatitudes of AIRSLMD and TOVS Path-B is linked to the temperature threshold of $230 \mathrm{~K}$ for the definition of ice cloud. To summarize:

- Most datasets show a similar seasonal cycle (Fig. 5). The agreement is better for physical properties than for bulk microphysical properties, because the latter are more affected by retrieval filtering and additional retrieval assumptions.

- Interannual variability includes natural processes that must be considered when analyzing trends.

- Global interannual variability lies between 0.02 and 0.03 in cloud amount, between $2.5 \%$ and $3.5 \%$ in relative high-level/low-level cloud amount, and around $2 \mathrm{~K}$ in cloud temperature.

Natural interannual variability increases when considering specific regions: The most prominent feature in regional interannual variability is associated with El Niño-Southern Oscillation. Monitoring long-term variations with these datasets requires consideration of many factors. Because of systematic variations of cloud properties with geographical location, time of day, and season, any systematic variations in sampling of these distributions can introduce artifacts in the long-term record. In addition, systematic changes in instrument calibration or biases between instruments that are part of an inter-instrument data record are also problematic. These have to be carefully investigated before attributing any detected trends to climate change. The fraction of the globe sampled within 
$12 \mathrm{~h}$, which we call the instantaneous sampling fraction, should be large so that all locations are observed with the same frequency during a month. Figure 6 presents the time series of monthly mean instantaneous sampling fractions of the globe (more details in section 2 of Stubenrauch et al. 2012) as well as deseasonalized anomalies in global monthly mean CA and CT of the available datasets
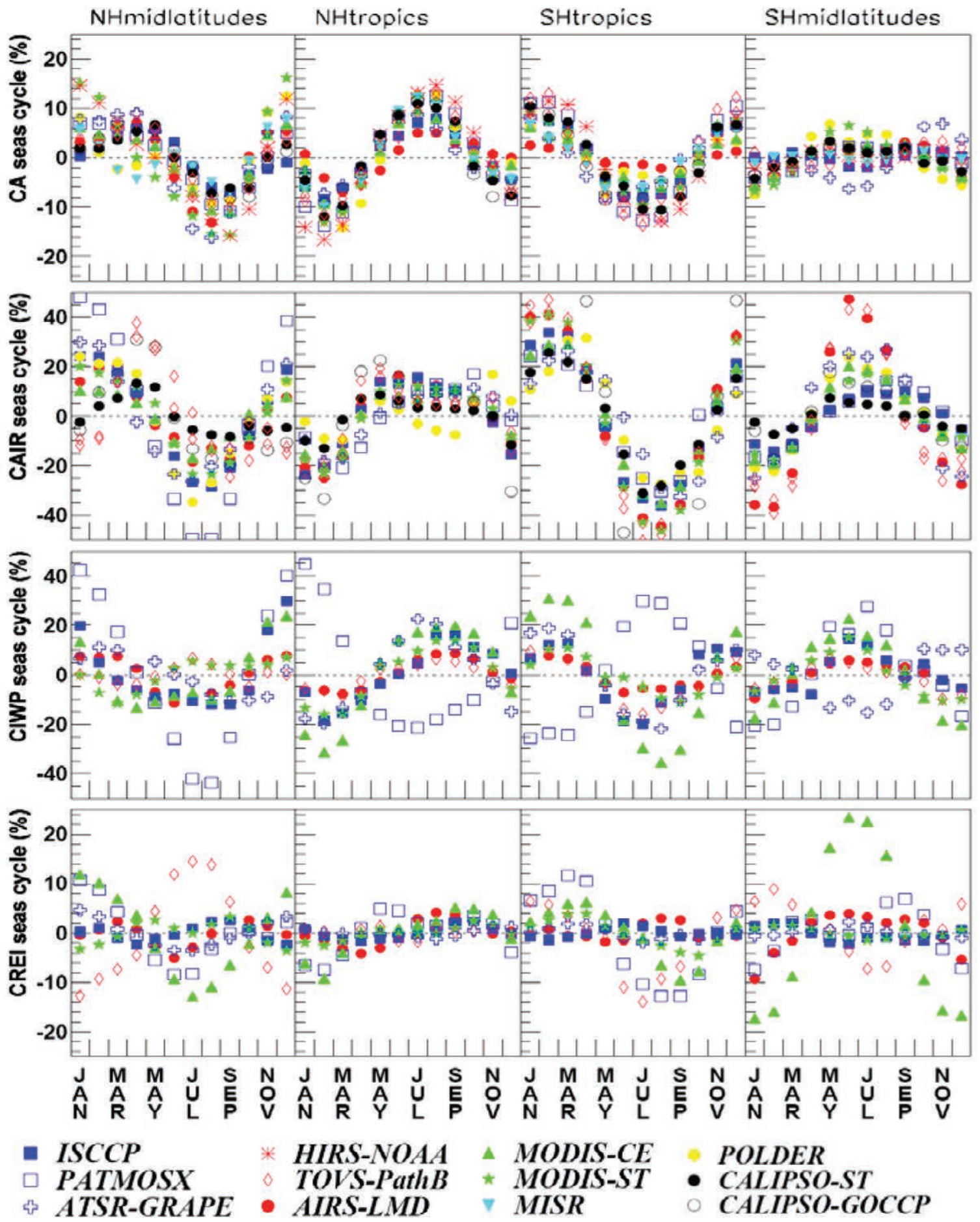

FIG. 5. Seasonal cycle (relative) of cloud amount, relative high-level ice cloud amount, ice water path, and effective ice crystal radius for four latitude bands: NH midlatitudes $\left(30^{\circ}-60^{\circ} \mathrm{N}\right)$, NH tropics $\left(0^{\circ}-30^{\circ} \mathrm{N}\right)$, SH tropics $\left(0^{\circ}-30^{\circ} \mathrm{S}\right)$, and $\mathrm{SH}$ midlatitudes $\left(30^{\circ}-60^{\circ} \mathrm{S}\right)$. Statistics are averaged over daytime measurements. 
over the corresponding time periods at a specific observation time. On average, the magnitude of the variations corresponds to the global mean interannual variability. ISCCP results including all daily observations (also shown in Fig. 6) are similar to the ones at 1600 local observation time. Detailed investigations by Rossow (annex 2 of Stubenrauch et al. 2012) on possible sources leading to spurious changes in the ISCCP CA time record show that, although they can change the magnitude of the slow CA variations by about one-third, they cannot account for all of the variation.

\section{CONCLUSIONS, RECOMMENDATIONS,} AND OUTLOOK. The GEWEX Cloud Assessment database, created by the participating teams, allowed for the first time a coordinated intercomparison of L3 cloud products of 12 global "state of the art" datasets. In addition to self-assessments (annex 1 of Stubenrauch et al. 2012), which show the matu- rity of the various datasets, the analyses have shown how cloud properties are perceived by instruments measuring different parts of the electromagnetic spectrum and how cloud property averages and distributions are affected by instrument choice as well as some methodological decisions. These satellite cloud products are very valuable for climate studies or model evaluation: Even if absolute values, especially those of high-level cloud statistics, depend on instrument (or retrieval) capability to detect and/ or identify thin cirrus, relative geographical and seasonal variations in the cloud properties agree very well (with only a few exceptions, like deserts and snow-covered regions). Probability density functions of radiative and bulk microphysical properties also agree well, when one considers retrieval filtering or possible biases due to partly cloudy pixels (e.g., Zhang and Platnick 2011; Pincus et al. 2012) and due to icewater misidentification. When comparing to climate models, observation time and view from above as well

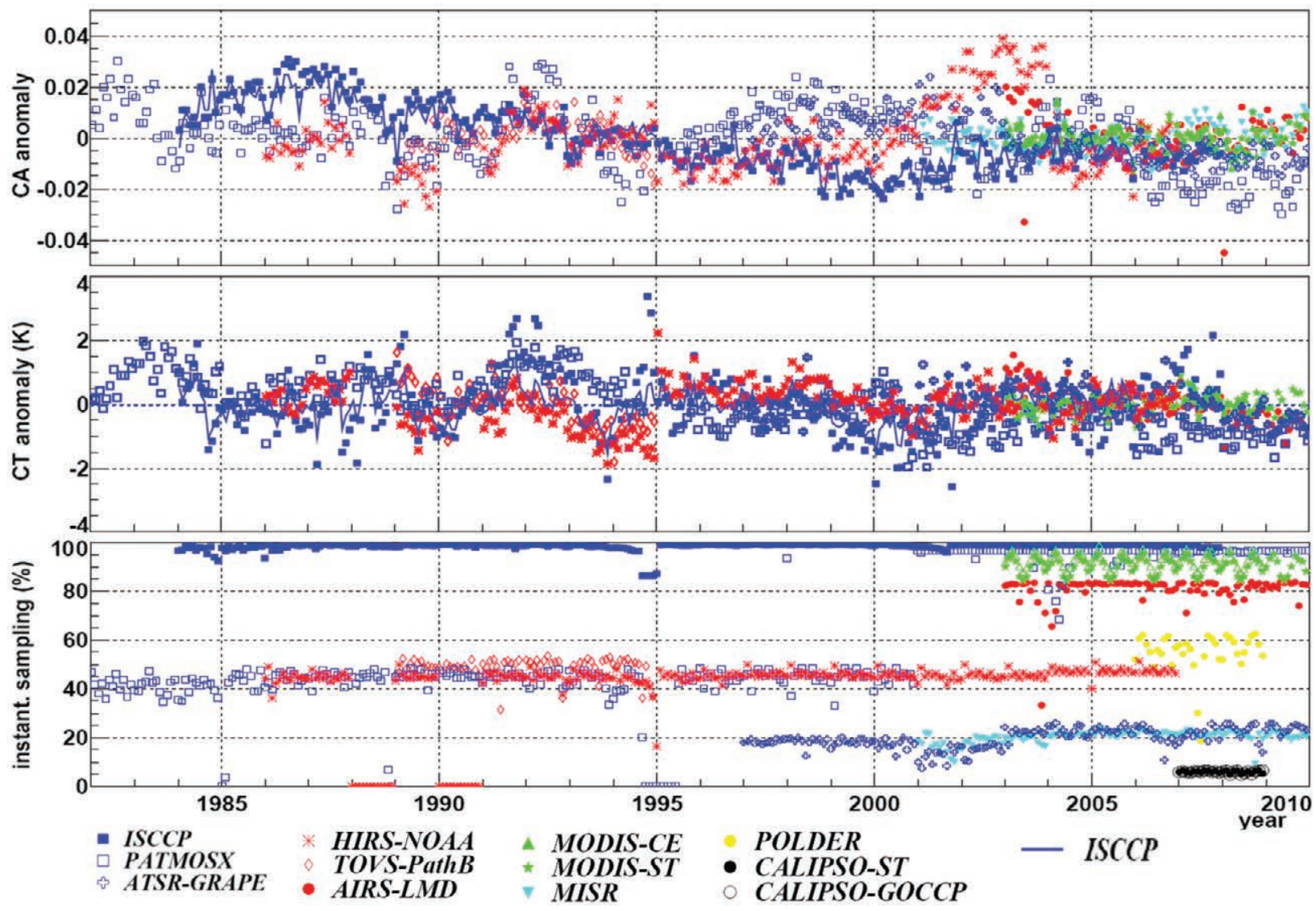

Fıg. 6. Time series of global CA and CT anomalies as well as of monthly mean instantaneous sampling fraction of the globe (at a specific local observation time) of the participating datasets. For each dataset the period covered in the GEWEX cloud assessment database is shown, with local observation time at I330 LT (I500 LT for ISCCP, I030 LT for ATSR-GRAPE, and I030 LT for MISR). ISCCP anomalies are also shown using the whole diurnal time statistics (blue line). 
as retrieval filtering have to be taken into account. This can be achieved either by simple methods (e.g. Hendricks et al. 2010) or by more sophisticated ones, like the Cloud Feedback Model Intercomparison Project (CFMIP) Observation Simulator Package (Bodas-Salcedo et al. 2011), which consists of individual simulators, with each corresponding to a specific cloud dataset (e.g., ISCCP, CALIPSO, MODIS, MISR, or CloudSat). One has to keep in mind that these simulators contain observation biases identified by this assessment but may still include other biases.

Global total cloud amount is about $0.68( \pm 0.03)$ when considering clouds with optical depth $>0.1$. This value increases to about 0.73 when including subvisible cirrus and decreases to about 0.56 for clouds with optical depth $>2$. Oceans are covered by about $0.10-0.15$ more cloudiness than land. About $40 \%-50 \%$ of all clouds seen from above are high-level clouds, only about $15 \%( \pm 5 \%)$ are midlevel clouds, and about $40 \%( \pm 3 \%)$ are single-layer low-level clouds. Global cloud amount and cloud temperature seem to be stable within the global mean interannual variability ( 0.03 and $2 \mathrm{~K}$, respectively).

ISCCP cloud properties have been tested by comparing resulting radiative fluxes at top of atmosphere and surface to those determined from Earth Radiation Budget instruments and surface measurements, respectively, revealing excellent quantitative agreement (Zhang et al. 2004; Kato et al. 2011; Raschke et al. 2012). At present, the ISCCP data record is being reprocessed. This kind of assessment should be repeated in regular intervals. The current GEWEX Cloud Assessment database will facilitate future activities but can also be used for model evaluations, since the multiple data products can be used to crosscheck on the observations. Coordinated comparison of satellite derived cloud properties continues as the EUMETSAT has initiated the Cloud Retrieval Evaluation Workshop (CREW; www.icare.univ-lillel.fr /crew/index.php/Welcome), focusing on detailed L2 data comparisons over limited areas and time periods. ESA also includes assessments of the essential climate variables retrieved within the climate change initiative.

ACKNOWLEDGMENTS. Our thanks go to the former workshop co-chairs B. Baum and C. G. Campbell; to many individual contributors who have attended the different workshops and helped in creating the GEWEX Cloud Assessment Database; and to the other product team members like Y. Chen, A. Menzie, E. Olson, F. Parol, A. Sayer, and D. Wylie. The authors also want to thank A. Feofilov for his fruitful comments and three anonymous review- ers for their thoughtful help to clarify the manuscript. The analyses were supported by CNRS and CNES, and the data of this database are being distributed by the IPSL Data Center Climserv.

\section{REFERENCES}

Ackerman, S. A., K. I. Strabala, W. P. Menzel, R. A. Frey, C. C. Moeller, and L. E. Gumley, 1998: Discriminating clear-sky from clouds with MODIS. J. Geophys. Res., 103 (D24), 32 141-32 157.

Astin, I., L. Di Girolamo, and H. M. Van de Poll, 2001: Baysian confidence intervals for true fractional coverage from finite transect measurements: Implications for cloud studies from space. J. Geophys. Res., 106, 17303-17310.

Baran, A., and L. Labonnote, 2007: On the reflection and polarisation properties of ice cloud. J. Quant. Spectrosc. Radiat. Transfer, 133, 1899-1912.

Bodas-Salcedo, A., and Coauthors, 2011: COSP: Satellite simulation software for model assessment. Bull. Amer. Meteor. Soc., 92, 1023-1043.

Chepfer, H., S. Bony, D. Winker, G. Cesana, J. L. Dufresne, P. Minnis, C. J. Stubenrauch, and S. Zeng, 2010: The GCM Oriented CALIPSO Cloud Product (CALIPSO-GOCCP). J. Geophys. Res., 115, D00H16, doi:10.1029/2009JD012251.

Cole, B. H., P. Yang, B. A. Baum, J. Riedi, L. C.Labonntoe, F. Thieuleux, and S. Platnick, 2012: Comparison of PARASOL observations with polarized reflectances simulated using different ice habit mixtures. J. Appl. Meteor. Climatol., 52, 186-196.

Di Girolamo, L., and R. Davies, 1997: Cloud fraction errors caused by finite resolution measurements. J. Geophys. Res., 102, 1739-1756.

—, A. Menzies, G. Zhao, K. Mueller, C. Moroney, and D. J. Diner, 2010: MISR level 3 cloud fraction by altitude algorithm theoretical basis. Jet Propulsion Laboratory Rep. JPL D-62358, 24 pp.

Ferlay, N., and Coauthors, 2010: Toward new inferences about cloud structures from multidirectional measurements in the oxygen A band: Middle-of-cloud pressure and cloud geometrical thickness from POLDER-3/PARASOL. J. Appl. Meteor. Climatol., 49, 2492-2507.

Frey, R. A., S. A. Ackerman, Y. Liu, K. I. Strabala, H. Zhang, J. Key, and X. Wang, 2008: Cloud detection with MODIS. Part I: Recent improvements in the MODIS cloud mask. J. Atmos. Oceanic Technol., 25, 1057-1072.

Goloub, P., M. Herman, H. Chepfer, J. Riedi, G. Brogniez, P. Couvert, and G. Séze, 2000: Cloud thermodynamical phase classification from the POLDER 
spaceborne instrument. J. Geophys. Res., 105, 14747-14759.

Guignard, A., C. J. Stubenrauch, A. J. Baran, and R. Armante, 2012: Bulk microphysical properties of semi-transparent cirrus from AIRS: A six year global climatology and statistical analysis in synergy with geometrical profiling data from CloudSat-CALIPSO. Atmos. Chem. Phys., 12, 503-525.

Han, Q.-Y., W. B. Rossow, and A. A. Lacis, 1994: Nearglobal survey of effective cloud droplet radii in liquid water clouds using ISCCP data. J. Climate, 7, 465-497.

— — _ J. Chou, K.-S. Kuo, and R. M. Welch, 1999: The effect of aspect ratio and surface roughness on satellite retrievals of ice-cloud properties. J. Quant. Spectrosc. Radiat. Transfer, 63, 559-583.

Heidinger, A. K., and M. J. Pavolonis, 2009: Gazing at cirrus clouds for 25 years through a split window. Part I: Methodology. J Appl. Meteor. Climatol., 48, 1100-1116.

—, A. T. Evan, M. J. Foster, and A. Walther, 2012: A naive Bayesian cloud detection scheme derived from CALIPSO and applied within PATMOS-x. J. Appl. Meteor. Climatol., 51, 1129-1144.

Hendricks, J., A. Falb, C. J. Stubenrauch, U. Lohmann, and C. Emde, 2010: A method for comparing properties of cirrus clouds in global climate models with those retrieved from IR sounder satellite observations. Meteor. Z., 19, 577-589.

Holz, R., S. A. Ackerman, P. Antonelli, F. Nagle, R. O. Knuteson, M. McGill, D. L. Hlavka, and W. D. Hart, 2006: An improvement to the high-spectralresolution $\mathrm{CO}_{2}$-slicing cloud-top altitude retrieval. J. Atmos. Oceanic. Technol., 23, 653-670.

Jin, Y., and W. B. Rossow, 1997: Detection of cirrus overlapping low-level clouds. J. Geophys. Res., 102, 1727-1737.

Kato, S., and Coauthors, 2011: Improvements of topof-atmosphere and surface irradiance computations with CALIPSO-, CloudSat-, and MODIS-derived cloud and aerosol properties. J. Geophys. Res., 116, D19209, doi:10.1029/2011JD016050.

Liao, X., W. B. Rossow, and D. Rind, 1995: Comparison between SAGE II and ISCCP high-level clouds. Part II: Locating cloud tops. J. Geophys. Res., 100, 1137-1147.

Lin, B., and W. B. Rossow, 1996: Seasonal variation of liquid and ice water path in nonprecipitating clouds over oceans. J. Climate, 9, 2890-2902.

_- P. Minnis, B. Wielicki, D. R. Doelling, R. Palikonda, D. F. Young, and T. Uttal, 1998: Estimation of water cloud properties from satellite microwave, infrared and visible measurements in oceanic environments. 2. Results. J. Geophys. Res., 103, 3887-3905.
Mace, G. G., and S. Benson-Troth, 2002: Cloud-layer overlap characteristics derived from long-term cloud radar data. J. Climate, 15, 2505-2515.

-, Q. Zhang, M. Vaughan, R. Marchand, G. Stephens, C. Trepte, and D. Winker, 2009: A description of hydrometeor layer occurrence statistics derived from the first year of merged Cloudsat and CALIPSO data. J. Geophys. Res., 114, D00A26, doi:10.1029/2007JD009755.

Maddux, B. C., S. A. Ackerman, and S. Platnick, 2010: Viewing geometry dependencies in MODIS cloud products. J. Atmos. Oceanic Technol., 27, 1519-1528.

Menzel, W. P., and Coauthors, 2008: MODIS global cloud-top pressure and amount estimation: Algorithm description and results. J. Appl. Meteor. Climatol., 47, 1175-1198.

Minnis, P., D. F. Young, C. W. Fairall, and J. B. Snider, 1992: Stratocumulus cloud properties from simultaneous satellite and island-based instrumentation during FIRE. J. Appl. Meteor., 31, 317-339.

—, P. W. Heck, and D. F. Young, 1993: Inference of cirrus cloud properties using satellite-observed visible and infrared radiances. Part II: Verification of theoretical cirrus radiative properties. J. Atmos. Sci., 50, 1305-1322.

— , and Coauthors, 2008a: Cloud detection in nonpolar regions for CERES using TRMM VIRS and Terra and Aqua MODIS data. IEEE Trans. Geosci. Remote Sens., 46, 3857-3884.

—, C. R. Yost, S. Sun-Mack, and Y. Chen, 2008b: Estimating the physical top altitude of optically thick ice clouds from thermal infrared satellite observations using CALIPSO data. Geophys. Res. Lett., 35, L12801, doi:10.1029/2008GL033947.

— , and Coauthors, 2011: CERES edition-2 cloud property retrievals using TRMM VIRS and Terra and Aqua MODIS data, Part I: Algorithms. IEEE Trans. Geosci. Remote Sens., 49, 4374-4400.

O'Dell, C. W., F. J. Wentz, and R. Bennartz, 2008: cloud liquid water path from satellite-based passive microwave observations: A new climatology over the global oceans. J. Climate, 21, 1721-1739.

Parol, F., and Coauthors, 2004: Capabilities of multiangle polarization cloud measurements from satellite: POLDER results. Adv. Space Res., 33, 1080-1088.

Pincus, R., S. Platnick, S. A. Ackerman, R. S. Hemler, and R. J. P. Hofmann, 2012: Reconciling simulated and observed views of clouds: MODIS, ISCCP, and the limits of instrument simulators. J. Climate, 25, 4699-4720.

Platnick, S., 2000: Vertical photon transport in cloud remote sensing problems. J. Geophys. Res., 105 (D18), 22919-22935. 
—, M. D. King, S. A. Ackerman, W. P. Menzel, B. A. Baum, J. C. Riedi, and R. A. Frey, 2003: The MODIS cloud products: Algorithms and examples from Terra. IEEE Trans. Geosci. Remote Sens., 41, 459-473.

Rädel, G., C. J. Stubenrauch, R. Holz, and D. L. Mitchell, 2003: Retrieval of effective ice crystal size in the infrared: Sensitivity study and global measurements from TIROS-N Operational Vertical Sounder. J. Geophys. Res., 4281, 108, doi:10.1029/2002JD002801.

Raschke, E., S. Kinne, and P. W. Stackhouse, 2012: GEWEX Radiative Flux Assessment (RFA), Volume 1: Assessment, a project of the World Climate Research Programme Global Energy and Water Cycle Experiment (GEWEX) Radiation Panel. WCRP Rep. 19/2012, 273 pp. [Available online at www .wcrpclimate.org/documents/GEWEX\%20RFAVolume\%201-report.pdf.]

Rossow, W. B., and R. A. Schiffer, 1999: Advances in understanding clouds from ISCCP. Bull. Amer. Meteor. Soc., 80, 2261-2287.

— , A. W. Walker, and L. C. Garder, 1993: Comparison of ISCCP and other cloud amounts. J. Climate, 6, 2394-2418.

Sayer, A. M., and Coauthors, 2011: Global Retrieval of ATSR Cloud Parameters and Evaluation (GRAPE): Dataset assessment. Atmos. Chem. Phys., 11, 3913-3936.

Scott, N. A., and Coauthors, 1999: Characteristics of the TOVS Pathfinder Path-B dataset. Bull. Amer. Meteor. Soc., 80, 2679-2701.

Sherwood, S. C., J.-H. Chae, P. Minnis, and M. McGill, 2004: Underestimation of deep convective cloud tops by thermal imagery. Geophys. Res. Lett., 31, L11102, doi:10.1029/2004GL019699.

Stephens, G. L., and Coauthors, 2002: The CloudSat mission and the A-Train. Bull. Amer. Meteor. Soc., 83, 1771-1790.

Stubenrauch, C. J., A. Chédin, R. Armante, and N. A. Scott, 1999a: Clouds as seen by satellite sounders (3I) and imagers (ISCCP). Part I: Evaluation of cloud parameters. J. Climate, 12, 2189-2213.

$-, \ldots, \ldots$, and ——, 1999b: Clouds as seen by satellite sounders (3I) and imagers (ISCCP). Part II: A new approach for cloud parameter determination in the 3I algorithms. J. Climate, 12, 2214-2223.

— - — - G. Rädel, N. A. Scott, and S. Serrar, 2006: Cloud properties and their seasonal and diurnal variability from TOVS Path-B. J. Climate, 19, 5531-5553.

_ , S. Cros, A. Guignard, and N. Lamquin, 2010: A sixyear global cloud climatology from the Atmospheric Infrared Sounder aboard the Aqua satellite: Statisti- cal analysis in synergy with CALIPSO and CloudSat. Atmos. Chem. Phys., 10, 7197-7214.

, W. B. Rossow, and S. Kinne, 2012: Assessment of global cloud datasets from satellites: A project of the World Climate Research Programme Global Energy and Water Cycle Experiment (GEWEX) Radiation Panel. WCRP Rep. 23/2012, 176 pp. [Available online at www.wcrp-climate.org/documents/GEWEX_ Cloud_Assessment_2012.pdf.]

Su, H., J. H. Jiang, J. Teixeira, A. Gettelman, X. Huang, G. Stephens, D. Vane, and V. S. Perun, 2011: Comparison of regime-sorted tropical cloud profiles observed by CloudSat with GEOS5 analyses and two general circulation model simulations, J. Geophys. Res., 116, D09104, doi:10.1029/2010JD014971.

Walther, A., and A. Heidinger, 2012: Implementation of the daytime cloud optical and microphysical properties algorithm (DCOMP) in PATMOS-x. J. Appl. Meteor. Climatol., 51, 1371-1390.

Wang, J., W. B. Rossow, T. Uttal, and M. Rozendaal, 1999: Variability of cloud vertical structure during ASTEX from a combination of rawinsonde, radar, ceilometer, and satellite data. Mon. Wea. Rev., 127, 2484-2502.

Wang, P.-H., R. E. Veiga, L. B. Vann, P. Minnis, and G. S. Kent, 2001: A further study of the method for estimation of SAGE II opaque cloud occurrence. J. Geophys. Res., 106, 12 603-12613.

Wielicki, B. A., and L. Parker, 1992: On the determination of cloud cover from satellite sensors: The effect of sensor spatial resolution. J. Geophys. Res., 97, 12799-12 823.

Winker, D. M., M. A. Vaughan, A. H. Omar, Y. Hu, K. A. Powell, Z. Liu, W. H. Hunt, and S. A. Young, 2009: Overview of the CALIPSO mission and CALIOP data processing algorithms. J. Atmos. Oceanic Technol., 26, 2310-2323.

Wylie, D. P., W. P. Menzel, H. M. Woolf, and K. I. Strabala, 1994: Four years of global cirrus cloud statistics using HIRS. J. Climate, 7, 1972-1986.

— D. L. Jackson, W. P. Menzel, and J. J. Bates, 2005: Trends in global cloud cover in two decades of HIRS observations. J. Climate, 18, 3021-3031.

Yang, P., H. Wei, H. L. Huang, B. A. Baum, Y. X. Hu, G. W. Kattawar, M. I. Mishchenko, and Q. Fu, 2005: Scattering and absorption property database for nonspherical ice particles in the near- through farinfrared spectral region. Appl. Opt., 44, 5512-5523

—, L. Bi, B. A. Baum, K.-N. Liou, G. W. Kattawar, M. I. Mishchenko, and B. Cole, 2013: Spectrally consistent scattering, absorption, and polarization properties of atmospheric ice crystals at wavelengths from 0.2 to $100 \mu \mathrm{m}$. J. Atmos. Sci., 70, 330-347. 
Zeng, S., F. Parol, J. Riedi, C. Cornet, and F. Thieuleux, 2011: Examination of POLDER/PARASOL and MODIS/Aqua cloud fractions and properties representativeness. J. Climate, 24, 4435-4450.

—, C. Cornet, F. Parol, J. Riedi, and F. Thieuleux, 2012: A better understanding of cloud optical thickness derived from the passive sensors MODIS/AQUA and POLDER/PARASOL in the A-Train constellation. Atmos. Chem. Phys., 12, 11 245-11 259.

Zhang, Y., W. B. Rossow, A. A. Lacis, V. Oinas, and M. I. Mishchenko, 2004: Calculation of radiative fluxes from the surface to top of atmosphere based on ISCCP and other global data sets: Refinements of the radiative transfer model and the input data, J. Geophys. Res., 109, D19105, doi:10.1029/2003JD004457.
Zhang, Z., and S. Platnick, 2011: An assessment of differences between cloud effective particle radius for marine water clouds from three MODIS spectral bands. J. Geophys. Res., 116, D20215, doi:10.1029/2011JD016216.

, P. Yang, G. Kattawar, J. Riedi, L.-C. Labonnote, B. A. Baum, S. Platnick, and H.-L. Huang, 2009: Influence of ice particle model on satellite ice cloud retrieval: Lessons learned from MODIS and POLDER cloud product comparison. Atmos. Chem. Phys., 9, 7115-7129.

, S. Platnick, P. Yang, A. K. Heidinger, and J. M. Comstock, 2010: Effect of ice particle size vertical inhomogeneity on the passive remote sensing of ice clouds, J. Geophys. Res., 115, doi:10.1029/2010JD013835. 